\title{
Instrumentation for accelerated life tests of concentrator solar cells
}

\author{
N. Núñez, ${ }^{1,2, a)}$ M. Vázquez,, ${ }^{1,2}$ J. R. González, ${ }^{1}$ F. J. Jiménez, ${ }^{2}$ and J. Bautista ${ }^{1}$ \\ ${ }^{1}$ Instituto de Energía Solar, Universidad Politécnica Madrid, Ciudad Universitaria $s / n, 28040$ Madrid, Spain \\ ${ }^{2}$ EUIT Telecomunicación, Universidad Politécnica Madrid, Carretera de Valencia Km7, 28031 Madrid, Spain
}

\begin{abstract}
Concentrator photovoltaic is an emergent technology that may be a good economical and efficient alternative for the generation of electricity at a competitive cost. However, the reliability of these new solar cells and systems is still an open issue due to the high-irradiation level they are subjected to as well as the electrical and thermal stresses that they are expected to endure. To evaluate the reliability in a short period of time, accelerated aging tests are essential. Thermal aging tests for concentrator photovoltaic solar cells and systems under illumination are not available because no technical solution to the problem of reaching the working concentration inside a climatic chamber has been available. This work presents an automatic instrumentation system that overcomes the aforementioned limitation. Working conditions have been simulated by forward biasing the solar cells to the current they would handle at the working concentration (in this case, 700 and 1050 times the irradiance at one standard sun). The instrumentation system has been deployed for more than $10000 \mathrm{~h}$ in a thermal aging test for III-V concentrator solar cells, in which the generated power evolution at different temperatures has been monitored. As a result of this test, the acceleration factor has been calculated, thus allowing for the degradation evolution at any temperature in addition to normal working conditions to be obtained.
\end{abstract}

\section{INTRODUCTION}

One important feature of conventional photovoltaic (PV) modules is their high- reliability figures, which are reflected by their long warranty times. ${ }^{1,2}$ New concentrator photovoltaics (CPVs) must accomplish these high-reliability figures to penetrate the market, as there are important international research and commercial interests in CPVs. Therefore, the quality, reliability, and power stability must be identified to offer similar warranties to conventional PV modules that currently are 25 years and are expected to increase to 30 years in the short future.

CPV modules are far more sophisticated than conventional flat silicon modules, which increase the number of possible reliability issues. ${ }^{3}$ These photovoltaic systems include optical elements to concentrate the solar light over the solar cell between 200-fold and 2000-fold. It is common for the optics to be divided into primary and secondary parts, the former being associated with the solar cell. The structure comprised by the solar cell and the secondary optic is called a receiver. The configuration, in turn, of these receivers in series or parallel depends on the particular configuration of the module.

In the CPV market, there are companies that manufacture both solar cells and modules as well as companies that manufacture modules with cells that are purchased by other companies. The same cells are used in various concentration sun levels for various manufactured modules. ${ }^{2}$ For this reason, the reliability of the solar cells must be assessed independently to guarantee the product to the companies that only manufacture modules.

\footnotetext{
a) Author to whom correspondence should be addressed. Electrónica Física, EUIT de Telecomunicación. Campus Sur-UPM, Km 7 Carretera de Valencia, 28031 Madrid, Spain. Electronic mail: neftali.nunez@upm.es.
}

Some years ago, the development of III-V concentrator solar cells using the same technology as was used in III-V mature optoelectronic devices, such as LEDs (light emitting diodes), was proposed. In particular, new high-power LEDs are very similar to III-V high-concentrator solar cells in terms of materials used, power density, and size. High-power LEDs have been commercially available for many years, and manufacturers have made a great effort to improve their operational lifetime. ${ }^{4} \mathrm{~A}$ life prediction based on this similarity has been performed by the authors, who observe that CPV solar cells can have similar lifetimes to those of conventional solar cells. ${ }^{5}$ However, there are important difficulties in the evaluation of reliability in some types of solar cells, ${ }^{6}$ particularly in CPV solar cells due to the need for illumination inside the climatic chamber and the need for highly concentrated light illumination. ${ }^{7}$ In 2008 , an innovative proposal for reliability analysis for concentrator solar cells with different types of accelerated tests and real-time operation evaluation was presented and applied to CPV solar cells to corroborate predicted lifetime data. ${ }^{1}$ The primary results of these tests showed that CPV III-V solar cells are a highly reliable device as has been reported elsewhere. In this paper, the instrumentation system used in the last of these innovative accelerated reliability tests is explained in detail.

Taking into account the fact that CPV systems are to compete with existing silicon flat module technologies, lifetimes in the range of 25 years should be achieved, as was previously mentioned. To test the reliability of devices that are expected to last such a long time, accelerated aging tests are needed. Presently, no solution has been provided to reach the level of concentrated light that this kind type of cells requires to function inside a climatic chamber. In the instrumentation presented here, this issue has been overcome by simulating the working conditions by forward biasing the solar cells at 
the current they would be required to handle under operational concentration conditions. It is important to highlight that these solar cells operate under high irradiation and suffer high thermal and electrical stresses. The former two situations are reproduced in the simulation of the working conditions performed in the method described here. ${ }^{3}$ However, the effect of solar irradiation should be analyzed with additional tests.

The simulation method uses programmable current generators to bias the solar cells at their operation current.

The acceleration tests evaluate the evolution of the relative maximum generated power of the cells P0/Pt (maximum power generated in the initial instant of test divide for maximum power generated during the develop of test). The required I-V curve under illumination experienced in the normal conditions needed to obtain the generated power for each cell has been derived from the dark I-V curve measured inside the climatic chamber using a method described by Antón et al. ${ }^{8}$

Two sets of experiments have been conducted on $1 \mathrm{~mm}^{2}$ gallium aresenide (semiconductor) (GaAs) single-junction solar cells using the method described in this paper, only the second of which was performed with this instrumentation. ${ }^{9}$ The first uses uncoated solar cells, ${ }^{10}$ and the second uses coated cells.

The first sets of test with uncoated cells have the advantage that the solar cell can be measured under a solar simulator, and this procedure is able to corroborate the evaluation of relative power degradation in darkness inside the climatic chamber.

CPVs work in outdoor ambient conditions, and concentrator solar cells are coated with silicone for photovoltaic application, which protects the cell against humidity and other externals agents. In the case of accelerated thermal tests with this instrumentation, the solar cells are also coated with silicone to reproduce working conditions. Previous tests in uncoated solar cells show that the main solar cell degradation mechanism is related to a dramatic decrease in the parallel resistance component of the perimeter, and this is in turn due to a deterioration of the perimeter area of the cells that are in contact with air. For this reason, in these tests, ${ }^{10}$ solar cells were coated with photovoltaic silicone (Wacker SilGel ${ }^{\circledR}$ 612 ), emulating the protection used in real conditions and mitigating or eliminating the degradation of the perimeter cell.

This work describes the instrumentation used in the second test, in which the solar cells were coated with silicone and biased at current levels equivalent to 700 and 1050 suns at three high-test temperatures. For the sake of controlling the evolution of cells only under thermal stress, unbiased solar cells have been used as a reference. ${ }^{11}$ The semiconductor structure of GaAs in the tested cells was grown using a metalorganic vapor phase epitaxy reactor, is a chemical vapor deposition method of epitaxial growth of materials for obtain III-V multijunction devices, and the cells were processed using optoelectronic techniques. The whole process was conducted in the facilities of the Instituto de Energía Solar Universidad Politécnica de Madrid.

This paper has been divided into five sections. The introduction and methodology have been described in Secs. I and
II, respectively, and the testing setup instrumentation and requirements are described in Sec. III. The discussions of instrumentation setup results and conclusions have been described in Secs. IV and V, respectively.

\section{METHODOLOGY DESCRIPTION}

This section describes the method used to simulate the working conditions and the method in which the generated power was measured in darkness inside the climatic chamber. The objective is to monitor the degradation of the generated power and to extrapolate this information to normal working conditions.

\section{A. Simulated working conditions}

Working conditions was simulated by forward biasing the solar cells at the current they would be required to handle at their operation concentration. These solar cells, which have an active area of $1 \mathrm{~mm}^{2}$, handle a current density of $250 \mathrm{~mA} / \mathrm{mm}^{2}$ at 1000 suns. The bias current is injected through the busbar (Fig. 1) of the solar cell and thus, only vertical conduction can be achieved. ${ }^{12,13}$ Considering the busbar area, working conditions at 700 and 1050 suns were simulated by forward biasing the solar cells at 112 and $168 \mathrm{~mA}$, respectively. Current generators were independently tuned to reach the desired current level in each solar cell. This test does not take into account light-induced degradation; therefore, specific tests must be conducted. However, light-induced degradation does not significantly affect CPV GaAs solar cells for two reasons: the optical of concentrator solar cells filter the ultraviolet radiation, which is the more energetic aging radiation, and GaAs has a direct band gap material with a highbreakdown voltage. This supposes that GaAs has high resistance to radiation damage and, therefore, is the material used in photovoltaic spatial systems.

\section{B. Generated power measurement}

The power generated by every solar cell should be evaluated under a suitable light source capable of producing a uniform pattern within the working concentration range. Currently, this is far from being possible inside a

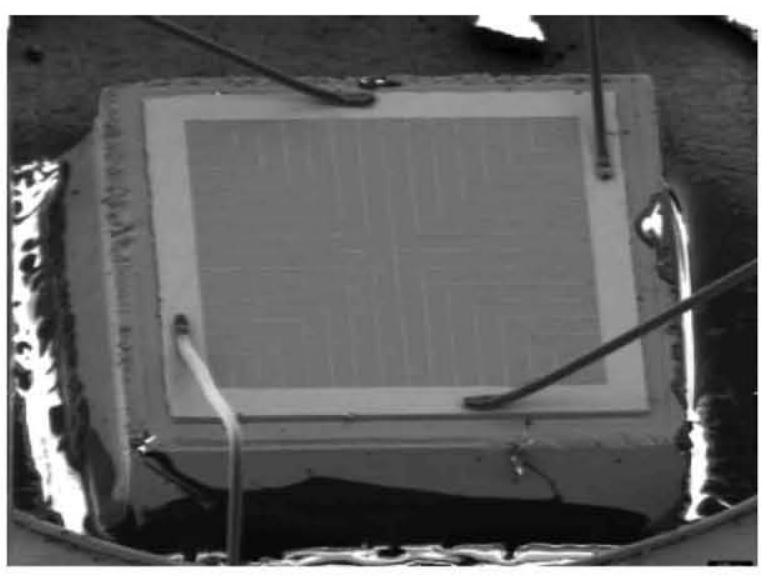

FIG. 1. Scanning electron microscope of a GaAs concentrator solar cell, showing the busbar with four-wire bondings and the active area. 
climatic chamber in darkness. To overcome this problem, the power generated by each solar cell is obtained, thereby reproducing the illumination I-V curve from the dark one, using a method that has been described elsewhere. ${ }^{8,9}$ This reproduction of the illumination I-V curve has been shown to be a suitable method, as the reproduced curves and the measured ones were in good agreement, with an average difference in fill factor of $5 \%$. The automatic system measures curve periodically to characterize the evolution of the generated power at the test temperature in time with respect to the initial value in $t=0 \mathrm{~h}$. The primary features of this measurement are the following:

- Dark I-V curves are recorded using the four-wire measurement to eliminate wiring and contact resistance.

- Dark I-V curves are very sensitive to electrical noise and temperature variations. Therefore, the following issues have been considered:

Current generation circuits have been physically isolated by means of relays during the dark I-V curve measurement.

$\square$ Prior to beginning measurement of the I-V curves for the cells, the system is programmed to wait until the junction cell temperature stabilizes to the climatic chamber temperature because the current injection heats the junction of the solar cells.

$\square$ The ambient temperature is permanently checked and recorded with each I-V curve measurement.

\section{INSTRUMENTATION SYSTEM}

This section describes the setup and analyzes the instrumentation requirements that the system must fulfill.

\section{A. Setup description}

The instrumentation system must be fully automatic due to the complexity and sensitivity of the solar cell measurements and the large quantity of data. The automatic system requires a software application for the control of the instrumentation, the generation of the data files, and the processing of the recorded data. A virtual instrument has been determined to be the best option for this instrumentation system.

The basic diagram of the instrumentation system is shown in Fig. 2. The main elements of this diagram are as follows, from left to right:

- A personal computer with a specific program developed in LABVIEW ${ }^{\circledR}$ that functions as a virtual instrument, ${ }^{14}$ and that controls, through a general purpose interface bus (GPIB), all of the instrumentation. With this software, the user selects the measurement frequency and controls the different test parameters (I-V curve measurement procedure and test identification among others). A subsequent process calculates the generated power of each individual solar cell.

- A Keithley ${ }^{\circledR} 3706$ switching system with a 3722 dual $1 \times 48$, high-density multiplexer card. Depending on the given instructions, this card is able either to se-

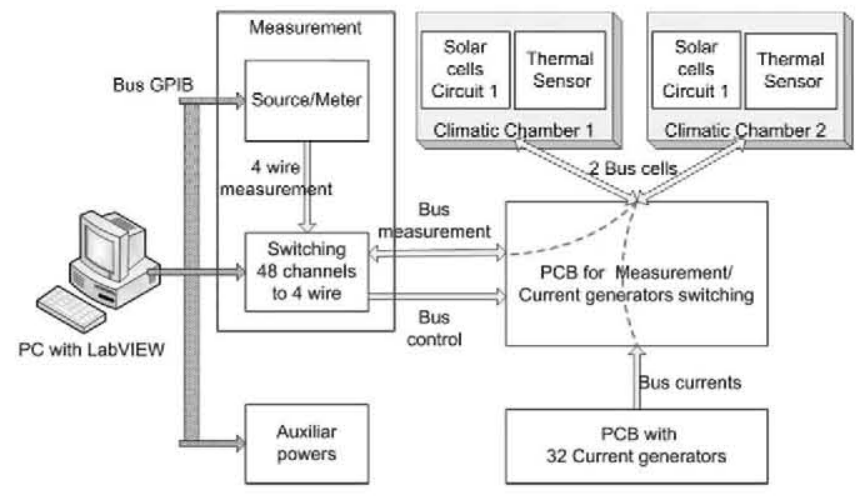

FIG. 2. (Color online) Basic block diagram system.

lect the temperature channel or to perform the fourwire electrical measurement. This system is capable of conducting two tests in two different climatic chambers at the same time. In addition, this equipment has enough digital outputs to control the status of the measurement/current generation switching circuits.

- A Keithley 2601 source/meter capable of measuring I-V curves according to the instructions selected by the user from the software. Voltage accuracy is $50 \mu \mathrm{V}$, and current accuracy is $1 \mathrm{pA}$.

- Thirty-two individual and adjustable current generators that have been specifically developed for these tests. These generators simulate the electrical stress of each individual solar cell. Each generator has been set using an Agilent 34401A multimeter with $6^{1 / 2}$ digits of resolution, with the cells inside the climatic chamber in thermal test conditions.

- A "printed circuit board (PCB) for measurement/current generation switching" that has been specifically designed for this project (Fig. 3). This element has a relay system for switching between biasing and measuring states, and the relays assembled on this board have a maximum contact resistance of $50 \mathrm{~m} \Omega$. Each circuit is divided into two subcircuits containing nine cells with a common anode. For measuring one of these subcircuits at the four-wire locations, only 20

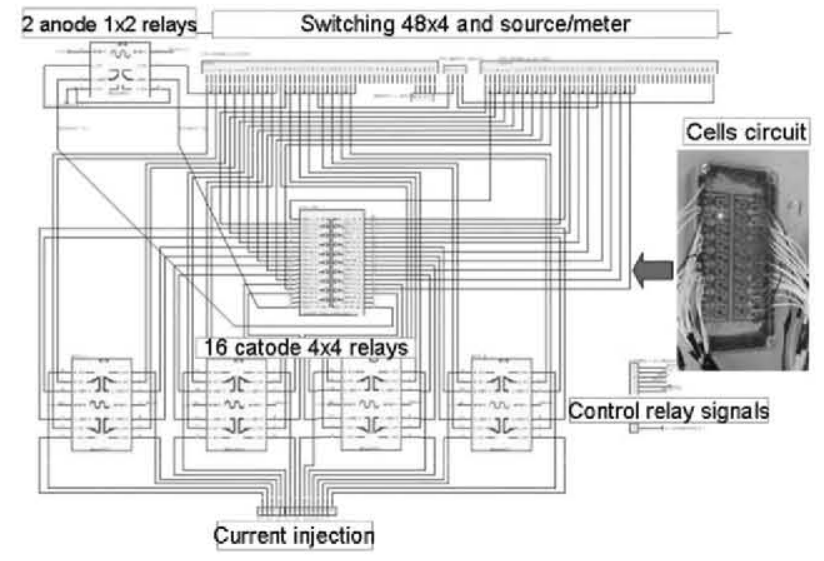

FIG. 3. (Color online) Schematic of half of the PCB for measurement/current generation switching. The solar cells circuit appears on the right during the dark I-V measurement state. 


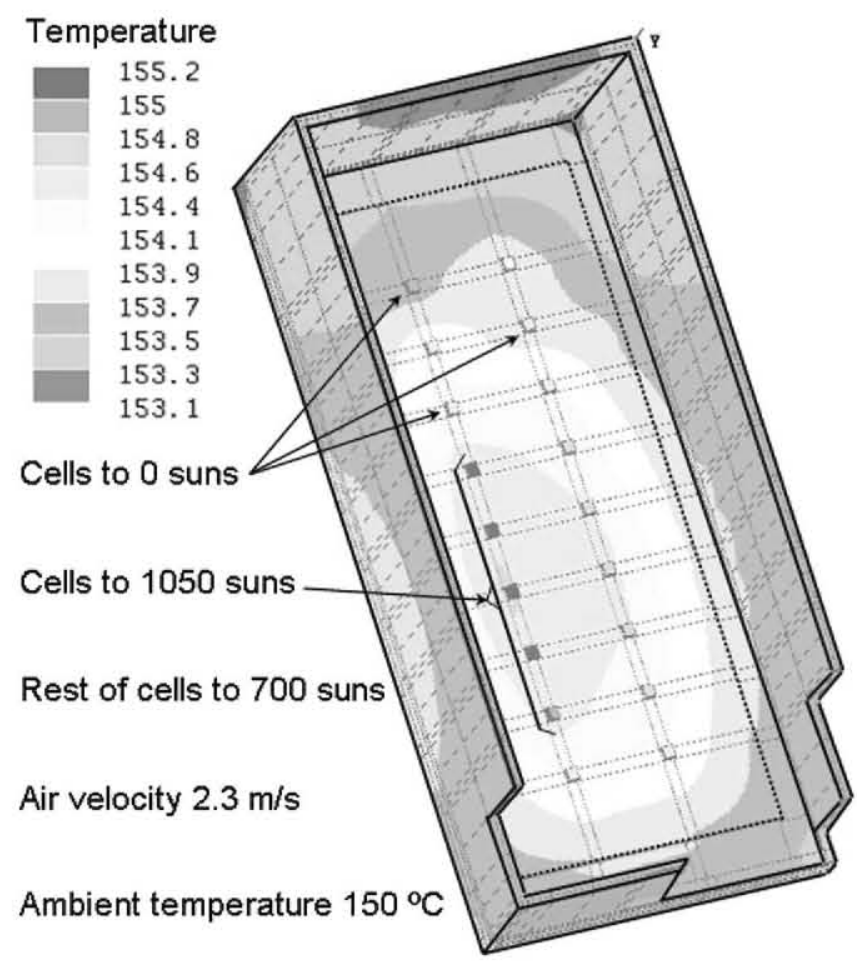

FIG. 4. (Color online) Thermal finite elements analysis of circuit tested at $150^{\circ} \mathrm{C}$. The silicone coating is not shown in this graph to visualize the GaAs solar cells chips.

wires are needed (two for each cell's cathode and two for the common anode). Because the return current is common for one of these subcircuits, this line needs a high-current relay.

- Two Heraeus-Vötsch climatic chambers have been used to conduct two different accelerated tests at the same time. The temperature fluctuation and deviation are $\pm 1^{\circ} \mathrm{C}$ according to the service manual for Vötsch Temperature System (VMT) 10/140 models.

- Solar cell circuits (Fig. 3). The circuits used to assemble the solar cells, when tested at high temperatures, require a substrate with high-temperature stability, low impedance tracks, and good thermal dissipation. To meet these requirements, the solar cells tested in this work have been encapsulated on direct bonded copper. These substrates were attached to an aluminum box with a high-thermal conductive adhesive. The boxes, in turn, were arranged on an alumina plate to have electrical isolation from the plate of the climatic chamber. The temperature of the junction for the tested solar cells has been evaluated using finite element software. The results of this simulation (Fig. 4) show an increment in temperature (less than $2.5^{\circ} \mathrm{C}$ at $150^{\circ} \mathrm{C}$ ) between cells without bias current and cells biased at the maximum bias current level. This low thermal incrementation implies that the difference in the degradation between cells in the aging test depends on the various current bias levels. The temperature of every solar cell has been measured using the recommendations of Childs et al. ${ }^{15}$ and the procedure described by

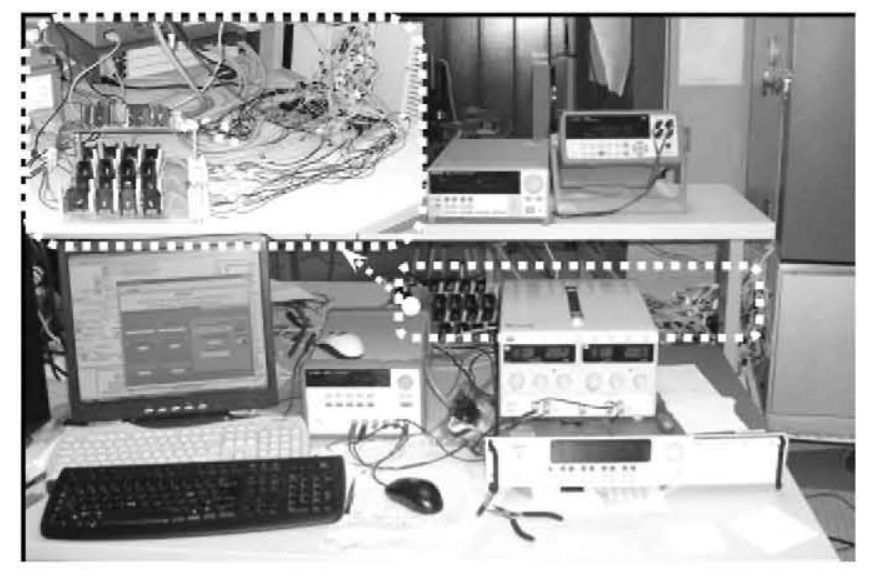

FIG. 5. (Color online) Photo of the instrumentation equipment.

Zhao et al. ${ }^{16}$ The results are in good agreement with the simulation.

Finally, Fig. 5 shows the instrumentation setup. To the right are the climatic chambers, to the left is the computer, in the center the measurement and auxiliary power supplies equipment, and behind the PCBs used as current generators and the PCB for measurement/current generation switching.

\section{B. Test requirements}

The instrumentation system must meet different requirements depending on the particular state, i.e., solar cells bias (current injection) or dark I-V curve measurement.

1. Solar cells bias (current injection): in this state, the solar cells are biased at a current level to simulate their working conditions. In this case, the following requirements should be considered:

- The current for each individual solar cell should be supplied by an individual current generator. This system is more complex than can be produced by a single current generator used in series for all of the cells because, in this case, an open circuit failure in a cell supposes the fail of all the tests. In our case, the failure of a current generator or cell would only affect a single solar cell.

- Current generators should be completely independent of one another, in a way that allows different current levels to be supplied to each solar cell. These generators should have accuracy better than $\pm 1 \%$. Otherwise, the uncertainty in the current supply would affect the degradation assessment.

- When the long duration of the tests is taken into consideration, the current provided by each generator should be periodically checked. Thus, small variations in the current injection can be controlled.

2. I-V curve measurement: in this state, the I-V curve of every solar cell is measured. This type of measurement has been widely used for the characterization of semiconductor devices. A full characterization of the solar cell requires the measurement of the I-V curve under concentrated light. However, as was previously men- 


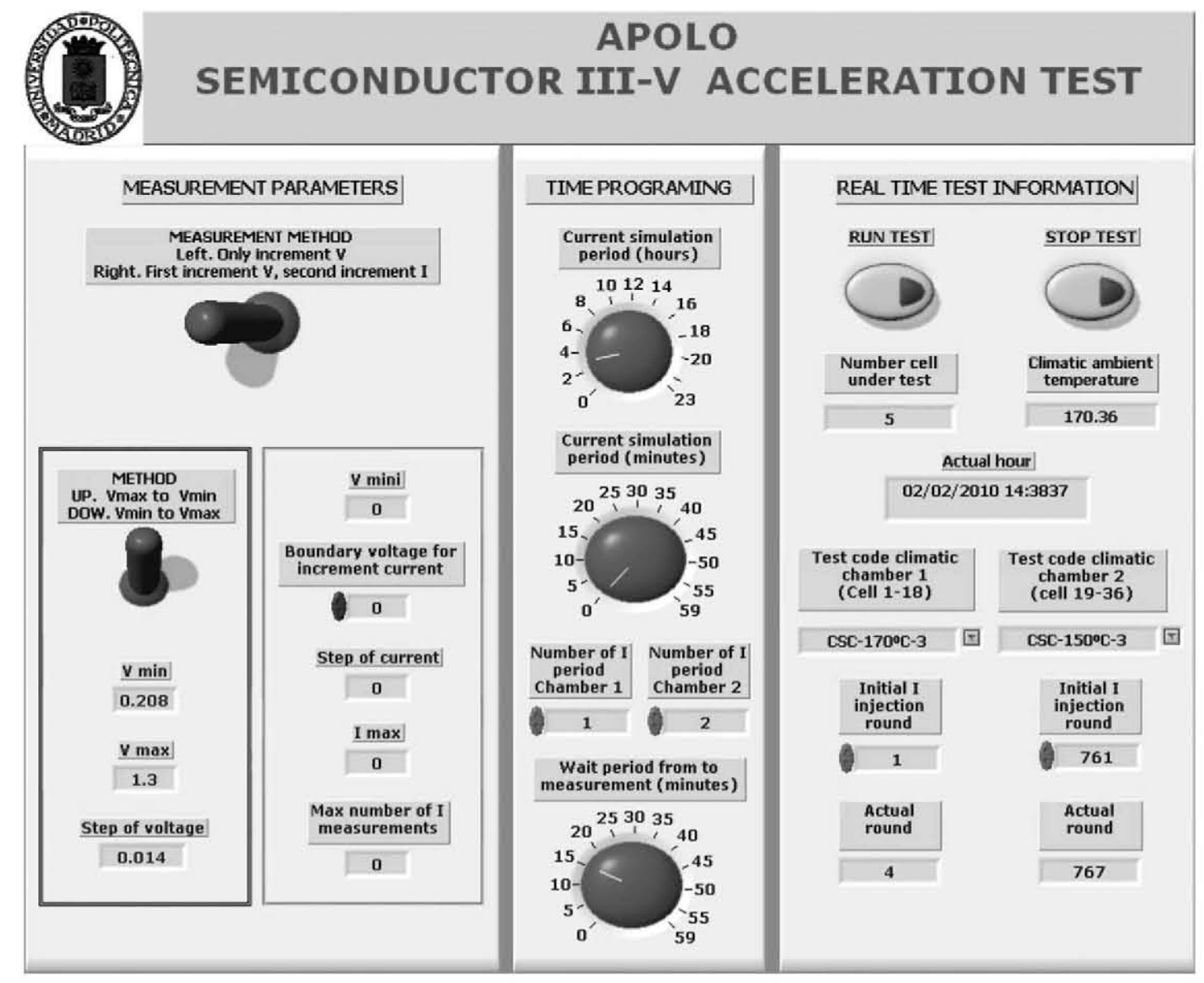

FIG. 6. (Color online) Control screen of tests.

tioned, this cannot be accomplished inside a climatic chamber. Therefore, ${ }^{8}$ a simulation of the illumination $\mathrm{I}-\mathrm{V}$ curve at the working concentration has been used in this test. In this case, the following requirements should be considered:

- The I-V curve is strongly influenced by temperature. To obtain accurate results, the temperature of the solar cells should be maintained in a stable manner and held equal to the ambient temperature during the test. To accomplish this, a time delay has been introduced following the creation of the bias state but prior to the measuring of the I-V curve.

- The range and resolution of the voltage measurement should be carefully determined for the characterization of the degradation of the solar cells in the best manner. Dark I-V measurement ranges and accuracy have been adapted to detect failure mechanism by means of a distributed 3D model.

- Different options can be chosen in the virtual instrument screen to measure the dark I-V curve (Fig. 6). In this case, a measurement from high to low voltage with constant step is illustrated. The reason for doing this is that the maximum power point is close to the high-voltage range; therefore, the heating of the device is minimized.

Figure 6 shows the control screen for the test, as programmed in LABVIEW. This screen allows for the selection of the aforementioned requirements for these tests. The parameters for measuring the dark I-V curve, the time interval for current injection and the waiting time before measuring, along with the real-time test information collection period (15 s each) allow for the monitoring of the situation and the progress of the two simultaneous tests.

The main parameters used for the measurement of the dark I-V curve for a GaAs high- concentrator solar cell are summarized in Table I.

Table II summarizes the injection current time period between measurements and other characteristics of the accelerated tests.

\section{DISCUSSION}

In this section, four topics will be addressed: the relevant results for reliability analysis, the precision and accuracy of the power measurements, a discussion of an alternative possible setup of the instrumentation, and future works.

The main objectives of the reliability analysis are to evaluate the time accelerated aging factor between tests at any solar cell junction temperatures, ${ }^{17,18}$ and to calculate the reliability and mean time to failure at normal working conditions. For thermal accelerated tests, Arrhenius' law is used to extrapolate the power time evolution for any junction temperature. To verify that the degradation mechanism follows Arrhenius' law, three different temperatures must be tested. These 
TABLE I. Parameters of the I-V curve measurement.

\begin{tabular}{|c|c|c|c|}
\hline Setup parameters & Conditions & Test values & Comment \\
\hline I-V curve initial voltage & Voltage@ $I=10^{-6}$ A & $0.208 \mathrm{~V}$ & $\begin{array}{l}\text { The adequate levels can change with the } \\
\text { temperature of the test }\end{array}$ \\
\hline I-V curve final voltage & $\begin{array}{l}1.3 \text { times the voltage at the } \\
\text { maximum power point }\end{array}$ & $1.3 \mathrm{~V}$ & \\
\hline Dark I-V maximum current level & $\begin{array}{l}1.3 \text { times the current at the } \\
\text { maximum power point }\end{array}$ & $1 \mathrm{~A}$ & $\begin{array}{l}\text { An excessive current stress in the } \\
\text { measurement would degrade the solar cell }\end{array}$ \\
\hline Voltage resolution & $10 \mu \mathrm{V}$ to $2 \mathrm{~V}$ limit & & \\
\hline Current resolution & $100 \mathrm{nA}$ to $1 \mathrm{~A}$ limit & & \\
\hline Dark I-V measuring process & $\begin{array}{l}\text { Constant V steps, from } V_{\max } \\
\text { to } V_{\min }\end{array}$ & $\begin{array}{l}\mathrm{V}_{\max }=1.3 \mathrm{~V} \\
\mathrm{~V}_{\min }=0.208 \mathrm{~V}\end{array}$ & \\
\hline Number of voltage steps & 50 to 100. & $\begin{array}{l}100 \text { points, } 14 \mathrm{mV} \\
\text { steps }\end{array}$ & \\
\hline Climatic chamber accuracy & $\pm 1{ }^{\circ} \mathrm{C}$ & $130^{\circ} \mathrm{C}$ & \\
\hline $\begin{array}{l}\text { Accuracy in ambient temperature } \\
\text { measurement close to the cells' assemblies }\end{array}$ & $\pm 0.4{ }^{\circ} \mathrm{C}$ & $\begin{array}{l}\text { PT100 type } 1 / 3 \\
\text { class B + (YST } \\
\text { AG - Y), four } \\
\text { wire }\end{array}$ & $\begin{array}{l}\text { Think film sensor of } 12 \mathrm{~mm}^{2} \text {, short response } \\
\text { time }\end{array}$ \\
\hline $\begin{array}{l}\text { Delay time between bias state and first cell } \\
\text { measurement }\end{array}$ & $15 \mathrm{~min}$ & $15 \mathrm{~min}$ & Delay measured previously to tests \\
\hline
\end{tabular}

tests are currently being conducted, but the analysis of the two finished tests, conducted at 130 and $150^{\circ} \mathrm{C}$ at 700 suns, which have a time acceleration factor of 3.8 , has been obtained between these two temperatures (Fig. 7). ${ }^{1}$ Preliminary results based on this acceleration factor and Arrhenius' law implies a time acceleration factor of more than 800 between the $150^{\circ} \mathrm{C}$ accelerated test and $65^{\circ} \mathrm{C}$ normal working conditions. This time acceleration factor allows reliability data regarding CPV solar cells to be obtained in a relatively short time.

The degradation mechanism of GaAs solar cells under accelerated tests has been analyzed by means of the 3D distribution model. This approach divides the solar cell into elementary units and assigns each unit to a suitable circuit model, depending on its geometry and position in the solar cell. The complete solar cell is modeled by the electrical circuit obtained by interconnecting every unit cell with its neighbor. The resulting equivalent circuit formed by thousands of elements is resolved using the SPICE circuit

TABLE II. Summary of test conditions.

\begin{tabular}{llll}
\hline \hline & $\begin{array}{l}\text { Different } \\
\text { concentration } \\
\text { sun levels of } \\
\text { temperature } \\
\text { test in circuits }\end{array}$ & $\begin{array}{l}\text { Period of injection } \\
\text { current between } \\
\text { measurements }\end{array}$ & $\begin{array}{c}\text { Length of } \\
\text { test }\end{array}$ \\
\hline $130^{\circ} \mathrm{C}$ & $\begin{array}{l}\text { 700 suns and } \\
\text { reference 0 suns }\end{array}$ & $18 \mathrm{~h}$ & $4232 \mathrm{~h}$ \\
& $\begin{array}{l}\text { reference cells. } \\
\text { suns cells. }\end{array}$ & $6 \mathrm{~h}$ & $5612 \mathrm{~h}$ \\
$150{ }^{\circ} \mathrm{C}$ & suns cells. & $6 \mathrm{~h}$ & Running \\
& 700 and 0 suns cells. & $3 \mathrm{~h}$ & R
\end{tabular}

simulator. $^{13}$ The application of this model revealed that the degradation occurs in the perimeter region of the cell, and the parameter of recombination current density at the perimeter increased by a factor of 4 .

The high precision of the power measurement has been achieved by means of repetitive measurement of dark I-V curves of the solar cells during $120 \mathrm{~h}$ at 257 thinsp; ${ }^{\circ} \mathrm{C}$ in a climatic chamber. This high-power measurement precision supposes high-relative power measurement accuracy. The relative power evolution is measured under current injection "continuously" at high-temperature tests, but we have also measured initial and final dark I-V curves under the same current conditions at $65^{\circ} \mathrm{C}$. The difference between the final average rel-

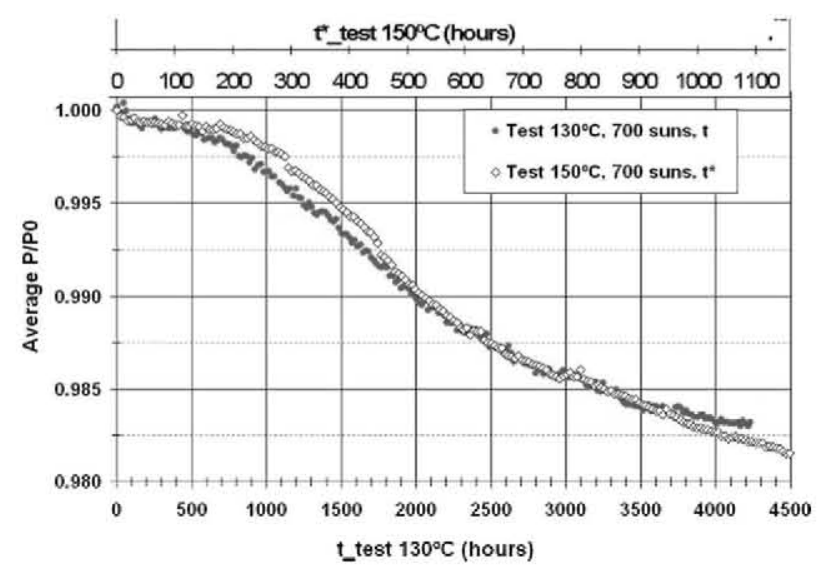

FIG. 7. (Color online) Average relative power with respect to the power at the initial time at the test temperature and 700 suns. $t=$ test time at $130^{\circ} \mathrm{C}$, $t^{*}=$ test time at $150^{\circ} \mathrm{C}$. 
ative powers measured at 130 and $65^{\circ} \mathrm{C}$, at 700 suns, is less than 0.0003 .

There are other alternatives to the instrumentation used for these tests. For example, the use of a unique current generator for a group of solar cells connected in series could be a good way of simplifying the design and manufacturing of the generators. However, a catastrophic failure in one solar cell would affect the current injection in the rest of the solar cells. Therefore, the main reason for using independent current generators instead of one connected in series is the higher tolerance to failures of the system, as a broken cell will not have influence over the rest of test in this system. It is necessary to remind the reader that this system works throughout the entire day without human control and that a failure in the instrumentation system could jeopardize the test, therefore invalidating the results.

The instrumentation presented in this work has been designed for small area CPV solar cells subject to a thermal stress. However, the setup can be deployed in tests with other stresses, such as humidity, current, and larger CPV solar cells. This setup is also being developed for the testing of multijunction solar cells.

\section{CONCLUSIONS}

This paper presents instrumentation that allows accelerated aging tests in simulated specific working conditions to be conducted for concentrator solar cells. The main conclusions are summarized below:

- Working conditions have been simulated by forward biasing the solar cells at the current level they would be required to handle at the working concentration. This test does not take into account light-induced degradation, and for that, specific tests must be conducted; however, light-induced degradation does not significantly affect CPV GaAs solar cells for two of the aforementioned reasons.

- The power evolution of each solar cell has been evaluated by measuring its dark I-V curve inside the climatic chamber. To obtain an accurate evolution of the power degradation with time, high-resolution equipment, with very low noise, is necessary. This system must also provide a very stable measurement across long time periods and constant current injection to obtain coherent results. The degradation can be very slow, depending on the quality of the devices and the period of measurement. For this reason, the control of the variables that influence the measurement is essential.

- This setup allows the evaluation, within a short period of time, of the durability of CPV cells. In addition, the reliability of different technologies can be compared. Optional features have been implemented to perform a screening process (burn-in) before assembling the solar cell in the receiver.
- The main objective of this instrumentation system is the evaluation of the failures and the determination of the power evolution with time, under controlled conditions, in an accelerated aging test. As a result of these tests, statistical and reliability tools can be used to extrapolate the results of the accelerated test, the power evolutions and reliability to normal working conditions.

Our effort is aimed at improving the manufacturing technology of concentrator solar cells, from the identification of their strengths and weaknesses. In this manner, the following generations of devices will be more reliable than the current ones and will be cost competitive and reliable when compared with conventional solar cells.

\section{ACKNOWLEDGMENTS}

The authors would like to thank Professor Carlos Algora, for his interest and comments regarding this paper. This work has been supported by the Spanish Ministerio de Educación y Ciencia through the CONSOLIDER-INGENIO 2010 program by means of the GENESIS FV project (CSD2006-004). The Spanish Ministerio de Ciencia e Innovación has also contributed via the SIGMASOLES project (PSS-440000-200930 ) and via the project with reference TEC2008-01226, as well as the Comunidad de Madrid under the NUMANCIA II program (S2009/ENE1477).

${ }^{1}$ C. Algora, Microelectron. Reliab. 50(9-11), 1193 (2010).

${ }^{2}$ S. Kurtz, Technical Report NREL (TP-520-43208), 2009.

${ }^{3}$ S. Kurtz, J. Granata, and M. Quintana, Conference Paper. NREL/CP-52044886 (2009).

${ }^{4}$ M. Vázquez, C. Algora, I. Rey-Stolle, and J. R. González, Prog. Photovoltaics 15, 477 (2007).

${ }^{5}$ F. C. Krebs and M. Jørgensen, Rev. Sci. Instrum. 74, 3438 (2003).

${ }^{6}$ F. J. Vorster and E. E. van Dyk, Rev. Sci. Instrum. 78, 013904 (2007).

${ }^{7}$ N. Núñez, J. R. González, M. Vázquez, C. Algora, and I. Rey-Stolle, in Safety, Reliability and Risk Analysis: Theory, Methods and Applications, Proceedings of ESREL 08, Valencia, Spain, 22-25 September 2008, S. Martorell, edited by C. Guedes Soares, and J. Barnett, Proceedings of ESREL 08, Valencia, Spain, 22-25 September 2008 (CRC Press, Taylor \& Francis, London, 2008), p. 1949.

${ }^{8}$ I. Antón, G. Sala, K. heasman, R. kern, and T. M. Bruton, Prog. Photovoltaics 11, $165(2003)$.

${ }^{9}$ J. R. González, M. Vázquez, N. Núñez, C. Algora, I. Rey-Stolle and B. Galiana, Microelectron. Reliab. 49, 673 (2009).

${ }^{10}$ J. R. González, M. Vázquez, N. Núñez, C. Algora, and P. Espinet, AIP Conf. Proc. 1277, 221 (2010).

${ }^{11}$ C. Algora, E. Ortíz, I. Rey-Stolle, V. Díaz, R. Peña, V. M. Andreev, V. P. Khvostikov, and V. D. Rumyantsev, IEEE Trans. Electron Devices 48(5), 840 (2001).

${ }^{12}$ B. Galiana, C. Algora, and I. Rey-Stolle, Prog. Photovoltaics 16, 331 (2008).

${ }^{13}$ P. Espinet, C. Algora, J. R. González, N. Núñez, and M. Vázquez, Microelectron. Reliab 50(9-11), 1875 (2010).

${ }^{14}$ F. J. Jimenez and J. De Frutos, Rev. Sci. Instrum. 75, 4497 (2004).

${ }^{15}$ P. R. N. Childs, J. R. Greenwood, and C. A. Long, Rev. Sci. Instrum. 71, $2959(2000)$.

${ }^{16}$ L. X. Zhao, E. J. Thrush, and C. J. Humphreys, J. Appl. Phys. 103, 024501 (2008).

${ }^{17}$ M. Vazquez and I. Rey-Stolle, Prog. Photovoltaics 16(5), 419 (2008).

${ }^{18}$ J. R. González, M. Vázquez, C. Algora, and N. Núñez, Prog. Photovoltaics 19(1), 113 (2011). 